\title{
Outcome in patients with differentiated thyroid cancer with negative diagnostic whole-body scanning and detectable stimulated thyroglobulin
}

\author{
K M van Tol, P L Jager ${ }^{1}$, E G E de Vries ${ }^{2}$, D A Piers ${ }^{1}$, H M Boezen ${ }^{3}$, W J Sluiter, R P F Dullaart and T P Links \\ Departments of Endocrinology, ${ }^{1}$ Nuclear Medicine, ${ }^{2}$ Medical Oncology and ${ }^{3}$ Epidemiology, University Hospital Groningen, University of Groningen, \\ The Netherlands
}

(Correspondence should be addressed to T P Links, Department of Endocrinology, University Hospital Groningen, PO Box 30.001, 9700 RB Groningen, The Netherlands; Email: T.P.Links@int.azg.nl)

\begin{abstract}
Background: Management of patients with differentiated thyroid carcinoma with negative diagnostic radioiodide scanning and increased serum thyroglobulin $(\mathrm{Tg})$ concentrations is a widely debated problem. High-dose iodine-131 treatment of patients who have a negative ${ }^{131} \mathrm{I}$ diagnostic wholebody scan (WBS) is advocated. However, the therapeutic benefit of this 'blind' treatment is not clear. Objective: To investigate the course of serum Tg during thyroid hormone suppression therapy (Tg-on) and clinical outcome in patients with negative diagnostic ${ }^{131}$ I scanning and increased serum Tg concentrations during thyroid hormone withdrawal (Tg-off), after treatment with high-dose ${ }^{131} \mathrm{I}$. Design: Retrospective single-center study. Methods: Fifty-six patients were treated with a blind therapeutic dose of $150 \mathrm{mCi}{ }^{131} \mathrm{I}$. Median followup from this treatment until the end of observation was 4.2 years (range 0.5-13.5 years).

Results: The post-treatment WBS revealed ${ }^{131}$ I uptake in 28 patients, but none in the remaining 28 patients. In this study the Tg-on values did not change after treatment in either the positive or the negative post-treatment WBS group. During follow-up, 18 of the 28 patients with a positive posttreatment WBS achieved complete remission, compared with 10 of the 28 patients with a negative post-treatment WBS. Nine patients in the negative group died, but no patients died in the positive post-treatment group $(P=0.001)$.

Conclusions: High-dose iodine treatment in diagnostically negative patients who have a negative posttreatment scan seems to confer no additional value for tumor reduction and survival. In patients with a positive post-treatment scan, high-dose iodine treatment can be used as a diagnostic tool to identify tumor location, and a therapeutic effect may be present in individual cases.
\end{abstract}

European Journal of Endocrinology 148 589-596

\section{Introduction}

The principal diagnostic tests used in the follow-up of patients with differentiated thyroid carcinoma are serum thyroglobulin ( $\mathrm{Tg}$ ) measurements and diagnostic whole-body radioiodine scanning $(1,2)$. Serum Tg can be measured during thyroid hormone suppression treatment (Tg-on) or after withdrawal of thyroid hormone (Tg-off). After total thyroidectomy and radioiodine ablation, an increased serum Tg-off value and a positive diagnostic radioiodine scan are good indicators of the presence of persistent, recurrent or metastatic thyroid cancer $(3,4)$. However, there is a management dilemma in the case of patients with a negative diagnostic radioiodine scan and an increased serum Tg-off value. Negative results from diagnostic radioiodine scanning may be caused by factors such as an insufficient increase in serum thyroid-stimulating hormone (TSH) or iodine contamination (5). Another explanation for negative diagnostic scanning is dedifferentation of the tumor, leading to a loss of its ability to trap iodine, while $\mathrm{Tg}$ production is still preserved. Finally, the presence of microscopic metastases too small to be visualized with a diagnostic dose of ${ }^{131} \mathrm{I}$ can give rise to negative scans.

Nowadays, in patients with negative results from diagnostic radioiodine scanning, an empirical therapeutic dose between 100 and $300 \mathrm{mCi}^{131} \mathrm{I}$, followed by a post-treatment whole-body scan (WBS), is advocated $(6-10)$. The purpose of this approach is twofold. First, post-treatment radioiodine scanning after high-dose ${ }^{131}$ I treatment is believed to be the most sensitive tool for localizing residual disease that is not revealed by diagnostic scanning with $2-5 \mathrm{mCi}{ }^{131} \mathrm{I}(6,11-14)$, 
enabling detected residual disease to be treated with other forms of therapy, such as surgery or radiotherapy. Secondly, small metastases not seen on diagnostic scanning may accumulate adequate amounts of ${ }^{131} \mathrm{I}$ after high-dose ${ }^{131} \mathrm{I}$ treatment, leading to a relevant reduction in tumor load. Several studies have shown a decrease in serum Tg-off after high-dose ${ }^{131}$ I treatment in patients with negative results from diagnostic radioiodide scanning $(13,15,16)$. However, in other studies, serum $\mathrm{Tg}$ remained the same or was increased $(6,17)$.

As the numbers of patients in these studies were small and follow-up data are scarce, it remains unclear whether such high-dose ${ }^{131}$ I treatment after negative results from diagnostic radioiodide scanning is of benefit for the patient. Recently, several reports have been published that show no additional effect of high-dose ${ }^{131}$ I treatment $(10,18,19)$, except for limited cases such as lung metastases (10). Moreover, it can be postulated that temporary stimulation of TSH caused by withdrawal of thyroid hormone will enhance tumor metabolism, as reflected by an increase in both Tg-on and Tg-off values in these patients (4). This may result in tumor progression. Another counter-argument is that treatment with ${ }^{131} \mathrm{I}$ in patients without sufficient accumulation of ${ }^{131} \mathrm{I}$, reflected by negative diagnostic ${ }^{131}$ I WBS, induces early anaplastic changes, resulting in a poor survival (20).

We studied a group of 56 patients with differentiated thyroid carcinoma with negative results from diagnostic ${ }^{131} \mathrm{I}$ scans and increased serum Tg-off values during thyroid hormone withdrawal after a so-called 'blind treatment' with high-dose ${ }^{131}$ I. The aim of the study was to investigate the course of serum Tg-on after high-dose ${ }^{131}$ I treatment and clinical outcome in patients with positive or negative post-treatment WBS results.

\section{Patients and Methods}

\section{Patients}

Between January 1978 and September 2000, 504 patients with differentiated thyroid carcinoma were treated in our institution. Patients underwent (near-) total thyroidectomy, followed by radioiodide ablation of residual functioning thyroid tissue 4-6 weeks later. A post-treatment WBS was performed 10 days after administration of the dose of ${ }^{131} \mathrm{I}$, using a two-headed gammacamera (Multispect 2; Siemens, Hoffman Estates, IL, USA) with a high-energy collimator.

Completeness of ablation was checked 3 months after the ablation procedure. Two weeks before undergoing diagnostic scanning, patients stopped taking triiodothyronine, and followed a low-iodine diet during that period. A diagnostic dose of $2 \mathrm{mCi}^{131} \mathrm{I}$ was applied and, in case of a negative scan, an additional diagnostic dose of $10 \mathrm{mCi}{ }^{131} \mathrm{I}$. A WBS was performed after $48 \mathrm{~h}$, and again at $72 \mathrm{~h}$ if the larger diagnostic dose had been necessary. Patients with persistent uptake and/or an increased $\mathrm{Tg}$ during hypothyroidism were treated every 3 months with $150 \mathrm{mCi}{ }^{131} \mathrm{I}$ until uptake on the post-treatment WBS had disappeared. When possible, additional surgery was performed. In between each cycle of treatment with ${ }^{131}$ I, patients received thyroid hormone suppression therapy with triiodothyronine, and visited the outpatient clinic. Serum Tg-on and TSH were measured at every visit at the clinic and each time after thyroid hormone withdrawal (Tg-off), for diagnostic or therapeutic ${ }^{131} \mathrm{I}$ scanning. In addition, at each visit a physical examination was carried out.

Patients were considered to be in complete remission if clinically detectable differentiated thyroid cancer was absent and diagnostic or post-treatment ${ }^{131}$ I WBS was negative combined with an undetectable serum Tg-off. If no subsequent diagnostic ${ }^{131} \mathrm{I}$ WBS was available after the last therapeutic dose of ${ }^{131} \mathrm{I}$, patients were also considered to be apparently in complete remission if serum Tg-on was undetectable for at least 6 months.

Follow-up included a visit to the outpatient clinic of the University Hospital Groningen every 4 months in the first 2 years, and annually thereafter. After 1980, it became the practice not to perform routine diagnostic ${ }^{131}$ I WBSs in patients with undetectable serum Tg-on concentrations during thyroid hormone suppression therapy. If concentrations became detectable during follow-up, thyroid hormone therapy was discontinued and a diagnostic ${ }^{131}$ I scan was performed.

We identified 56 patients who were treated with a therapeutic dose of $150 \mathrm{mCi}{ }^{131} \mathrm{I}$, because of detectable serum Tg-off without $\mathrm{Tg}$ antibodies, despite a negative WBS after 2 or $10 \mathrm{mCi}$ (or both) doses of ${ }^{131}$ I. Follow-up after this 'blind treatment' was at least 6 months.

\section{Laboratory measurements}

Serum Tg was measured from 1978 until 1984 using a homemade radioimmunoassay. From 1984 until 1989 a commercially available radioimmunoassay (Cis Bio International, Gif-sur-Yvette, France) was used, with a lower limit of detection of $3.0 \mathrm{ng} / \mathrm{ml}$. From 1989, the limit of detection of this radioimmunoassay was further decreased, to $1.5 \mathrm{ng} / \mathrm{ml}$. A validated conversion factor was used for serum $\mathrm{Tg}$ concentrations measured before 1989 to enable comparison with the serum $\mathrm{Tg}$ concentrations measured by the radioimmunoassay used since 1989. In case of an undetectable serum $\mathrm{Tg}$, the presence of $\mathrm{Tg}$ antibodies was evaluated by comparison of standard $\mathrm{Tg}$ and the patient's serum sample. Serum TSH was measured by a chemoluminescence immunoassay (Amersham, Little Chalfont, UK) that had a normal range of $0.3-5.0 \mathrm{mU} / \mathrm{l}$. 


\section{Statistical analysis}

Statistical analysis was performed using the SPSS 10.0 for Windows (SPSS Inc., Chicago, IL, USA). Data are expressed as medians and range, unless stated otherwise. Tests were two-sided, and a $P$-value less than 0.05 was considered to be significant. Differences between groups were tested using the $\chi^{2}$ test with continuity correction or the Mann-Whitney U-test, as appropriate. The Wilcoxon signed rank test was used to evaluate changes in serum $\mathrm{Tg}$ within the groups and the Wilcoxon rank sum test was applied to compare serum $\mathrm{Tg}$ concentrations between the groups. Multivariate analysis was performed according to a logistic regression model. Survival rates were estimated using Kaplan-Meier with log-rank.

\section{Results}

\section{Patients' characteristics}

'Blind ${ }^{131}$ I treatment' was performed in 56 patients (34 women and 22 men) with a median age of 54 years (range 22-82 years). Thirty-two patients presented with papillary thyroid carcinoma, 14 with a follicular carcinoma and 10 patients with a Hürthle cell carcinoma (Table 1). Median follow-up from initial diagnosis until the performance of the blind treatment was 0.8 years (range 0.3-13.6 years). In 34 patients, the reason for blind treatment was a negative post-ablative WBS; serum Tg-off was increased. The other 22

Table 1 Characteristics of the patients treated with high-dose radioiodine because of detectable serum $\mathrm{Tg}$-off values and negative results of diagnostic radioiodine scanning. The patients are divided into groups with positive or negative post-treatment WBS findings.

$\begin{array}{lrrr}\hline & \multicolumn{2}{c}{\text { Post-treatment WBS findings }} & \\$\cline { 2 - 3 } & \text {$\left.Positive }(n=28) & \text { Negative }(n=28) & \boldsymbol{P} \\ \hline \text { Sex } & & & \\ \text { Male } & 12 & 10 \\ \text { Female } & 16 & 18\end{array}\right)$

* No data available about the initial tumor size in six patients $(11 \%)$; three in each group. patients had received one or more additional treatment cycles with high-dose ${ }^{131} \mathrm{I}$, before a negative diagnostic WBS was recorded and serum Tg-off was still increased. No differences between these two groups were found concerning patient characteristics, the course of their disease or outcome parameters. The median cumulative dose of radioiodine used before the blind treatment was given was $150 \mathrm{mCi}{ }^{131} \mathrm{I}$ (range $50-650 \mathrm{mCi}{ }^{131} \mathrm{I}$ ). Median follow-up from the blind therapeutic dose until the end of observation was 4.2 years (range $0.5-13.5$ years).

\section{Results of post-treatment WBS}

Among the 56 blindly treated patients, 28 showed uptake of iodine at the post-treatment WBS and 28 patients had negative results from their post-treatment WBS (Table 1). There were no differences in sex, histology or the presence of cervical lymph-node or distant metastases at diagnosis, but in the group with negative post-treatment WBS results, more patients had presented with extrathyroidal growth of the tumor. No differences were found between the groups with respect to duration of follow-up $(P=0.95)$.

In the 28 patients with positive post-treatment WBS results, uptake was found seven times in the thyroid bed, six times in the neck, 12 times in the mediastinum, twice in the lungs, twice in the liver and once in a cervical vertebra. In three instances, undefined abdominal uptake was found that could not be confirmed with other imaging studies such as ultrasonography and computed tomography scanning.

Multivariate analyses of determinants contributing to a negative result of the post-treatment WBS are shown in Table 2. Only the presence of extrathyroidal growth at presentation was a prognostic factor.

\section{Serum Tg measurements}

Serum TSH concentration at time of administration of the blind treatment dose of ${ }^{131} \mathrm{I}$ was of an adequately high value (median $67 \mathrm{mU} / \mathrm{l}$, range $17.8-211 \mathrm{mU} / \mathrm{l}$ ). Serum Tg-on values were measured 6-12 weeks

Table 2 Multivariate analyses of factors contributing to a negative post-treatment WBS.

\begin{tabular}{|c|c|c|c|}
\hline Variable & Odds ratio & $95 \% \mathrm{Cl}$ & $\boldsymbol{P}$ \\
\hline Sex (male vs female) & 0.7 & 0.2 to 3.0 & 0.67 \\
\hline Age (10-year increments) & 0.8 & 0.6 to 1.3 & 0.43 \\
\hline Histology (FTC+H vs PTC) & 1.3 & 0.2 to 7.3 & 0.77 \\
\hline $\begin{array}{l}\text { Extrathyroidal disease } \\
\text { (T4 vs T0-T3) }\end{array}$ & 6.0 & 1.2 to 30.3 & 0.03 \\
\hline Lymph-node metastases (N1 vs N0) & 0.8 & 0.2 to 3.8 & 0.74 \\
\hline $\begin{array}{l}\text { Tg-on }{ }^{\text {prior }} \text { (detectable vs } \\
\text { undetectable) }^{\text {a }}\end{array}$ & 3.3 & 0.8 to 13.7 & 0.11 \\
\hline
\end{tabular}

$\mathrm{Cl}$, confidence interval; FTC, follicular thyroid cancer; PTC, papillary thyroid cancer; $\mathrm{H}$, Hürthle cell carcinoma. 
before the blind therapeutic dose $\left(\mathrm{Tg}-\mathrm{on}^{\text {prior }}\right)$ and $3-6$ months after the blind therapeutic dose $\left(\mathrm{Tg}\right.$-on $\left.{ }^{\text {after }}\right)$. At both times, patients had adequately suppressed TSH. As a consequence of the treatment procedure, no Tg-off measurements during follow-up were available for evaluation in most patients. Serum Tg-on ${ }^{\text {prior }}$, Tg-off and Tg-on ${ }^{\text {after }}$ were greater in the patients with a negative post-treatment WBS (Table 3). Tg-on ${ }^{\text {prior }}$ was below the limit of detection in 23 patients [in 16 patients in the group with a positive post-treatment WBS and in seven patients in the group with a negative post-treatment WBS $(P=0.02)]$. In three patients, the Tg-on ${ }^{\text {prior }}$ value was missing. Serum Tg-on ${ }^{\text {after }}$ remained undetectable in 24 patients, decreased in 12 patients and increased in 17 patients (Table 4 , Fig. 1). Serum Tg-on ${ }^{\text {after }}$ did not become detectable in any of the patients who had an undetectable serum $\mathrm{Tg}$-on $^{\text {prior }}$. In six patients, $\mathrm{Tg}$-on ${ }^{\text {after }}$ became undetectable (three in each group). The serum Tg-on ${ }^{\text {prior }}$ and serum Tg-on ${ }^{\text {after }}$ values of the whole group were not significantly different. In addition, there were no differences between the groups with respect to change in serum Tg-on values before and after blind treatment.

\section{Outcome and follow-up}

During follow-up, patients were treated with several treatment modalities, depending on the results of the post-treatment WBS, serum Tg-on values and other radiological imaging findings (Table 5). Patients with a positive post-treatment WBS more often received additional treatment, compared with the patients with negative results from post-treatment WBS $(P=0.007)$. This difference was caused by continuing

Table 3 Serum Tg-values before $\left(\mathrm{Tg}_{\mathrm{on}}{ }^{\text {prior }}\right)$ and after $\left(\mathrm{Tg}^{-o \mathrm{n}^{\text {after }}}\right)$ the blind therapeutic dose of ${ }^{131} \mathrm{I}$ and on the day of the blind therapeutic dose (Tg-off).

\begin{tabular}{|c|c|c|c|}
\hline & \multicolumn{2}{|c|}{ Post-treatment WBS findings } & \multirow[b]{2}{*}{$\boldsymbol{P}$} \\
\hline & Positive & Negative & \\
\hline $\begin{array}{l}\text { Tg-on }^{\text {prior }}(\mathrm{ng} / \mathrm{ml}) \\
\text { Tg-off (ng/ml) }\end{array}$ & $\begin{array}{l}<1.5(<1.5-47) \\
11.0(2.0-665)\end{array}$ & $\begin{array}{l}2.8(<1.5-2000) \\
32.5(1.7-10700)\end{array}$ & $\begin{array}{l}0.02 \\
0.02\end{array}$ \\
\hline Tg-on after (ng/ml) & $<1.5(<1.5-415)$ & $2.7(<1.5-33000)$ & 0.04 \\
\hline
\end{tabular}

Values are median (range).

Table 4 Change in serum Tg between serum $\mathrm{Tg}^{-o n^{\text {prior }}}$ and $\mathrm{Tg}^{-o \mathrm{n}^{\text {after }}}$ in both groups of patients.

\begin{tabular}{lcc}
\hline & \multicolumn{2}{c}{ Post-treatment WBS findings } \\
\cline { 2 - 3 } & Positive (No.) & Negative (No.) \\
\hline Decrease & 3 & 9 \\
Unchanged & 16 & 8 \\
Increase & 8 & 9 \\
Missing & 1 & 2 \\
\hline
\end{tabular}

high-dose ${ }^{131}$ I treatment and not by additional surgery or external radiotherapy. Of the 28 patients with positive results from post-treatment WBS, 18 (64\%) ultimately achieved complete remission, compared with 10 of the 28 patients $(36 \%)$ with negative posttreatment WBS results $(P=0.06)$. In the negative post-treatment WBS group, nine patients died during follow-up because of their disease, as compared with none in the positive post-treatment WBS group. This led to different survival rates between the groups (Fig. 2). The 5-year survival was $100 \%$ in the group with a positive post-treatment WBS and 76\% in the group with a negative post-treatment WBS $(P=0.001)$.

\section{Discussion}

In this study we have reported the results of treatment with a blind therapeutic dose of $150 \mathrm{mCi}{ }^{131} \mathrm{I}$ in 56 patients. Of these patients, $50 \%$ showed a positive post-treatment WBS and the remaining 50\% had negative results from the post-treatment scan. We found no differences between the course of Tg-on values in the negative and positive post-treatment groups. There was, however, a striking difference in final outcome between the patients with a positive and a negative post-treatment WBS. Among those with a positive post-treatment WBS, none died of their disease during the follow-up period, whereas among those with a negative post-treatment scan nine died as a consequence of thyroid cancer (5-year survival $100 \%$ compared with $76 \%, P=0.001$ ).

It is unlikely that stunning is responsible for the negative findings on post-treatment WBS, because of the short time span between the applied diagnostic and therapeutic doses (21). In addition, iodine contamination was very unlikely in our patients, because of their low-iodide diet. We have shown previously that the diet described results in low iodine excretion (22). The findings of several studies support the use of blind treatment with high-dose ${ }^{131} \mathrm{I}$ in cases of negative diagnostic scanning and increased serum $\mathrm{Tg}$, because a post-treatment decline in serum $\mathrm{Tg}$ was observed (Table 6) $(6,13,15,23,24)$. Most studies describe the treatment results only in patients with a positive post-treatment WBS, but the number of patients and follow-up data in these studies were limited (Table 6). Moreover, data in these studies are poorly comparable, because of different criteria for effect that were studied. Only the recent study by Pacini et al. (10) was able to differentiate between blind treatment and no treatment in patients with negative results from diagnostic scanning and detectable Tg-off. Pacini's group observed a frequent normalization of serum Tg-off, even in those who did not receive treatment. This observation was confirmed in the very recently published study by Baudin et al. (25). Patients with lung metastases and, 


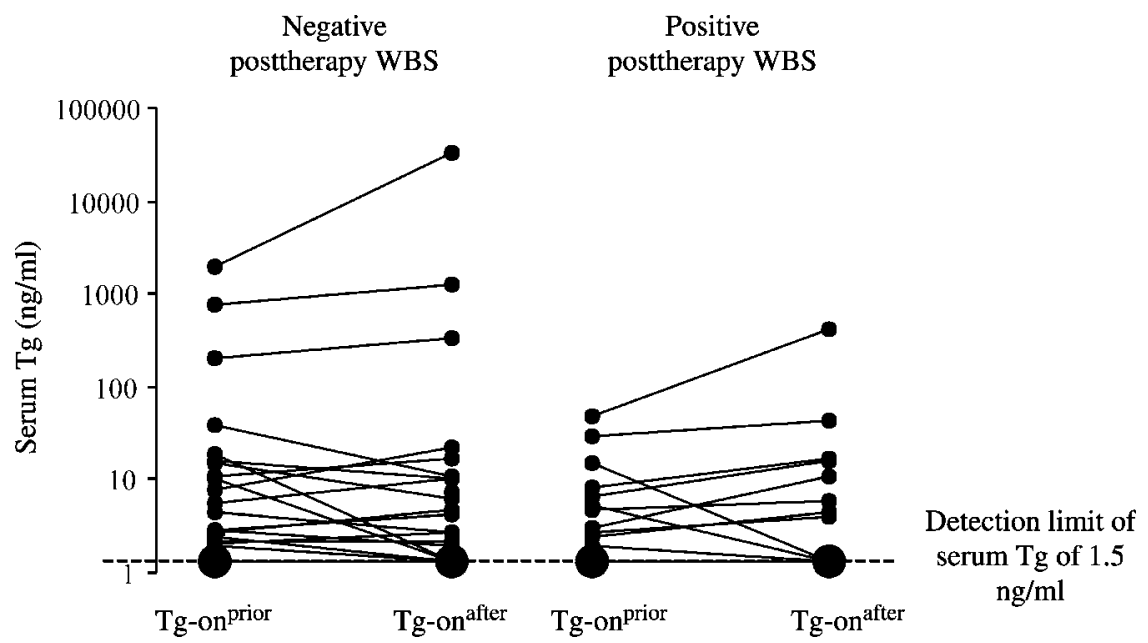

Figure 1 The course of serum Tg-on before and after blind treatment in the individual patients $(\bullet)$ grouped according to a negative or a positive post-treatment WBS. The large solid black circles, placed at the limit of detection, represent seven patients before and 11 patients after blind treatment in the negative post-treatment group and 16 and 19 patients, respectively, in the positive post-treatment group.

Table 5 Additional treatment in the patients given blind treatment with ${ }^{131}$ I.

\begin{tabular}{lcc}
\hline & \multicolumn{2}{c}{ Post-treatment WBS findings } \\
\cline { 2 - 3 } & Positive (No.) & Negative (No.) \\
\hline No treatment & 7 & 17 \\
Additional $^{131}$ I treatment & 14 & 3 \\
Surgery & 1 & 3 \\
Radiotherapy & - & 1 \\
Radioiodine and surgery & 3 & 2 \\
Radioiodine and radiotherapy & 2 & 1 \\
Surgery and radiotherapy & - & 1 \\
Radioiodine, surgery & 1 & - \\
$\quad$ and radiotherapy & \multicolumn{2}{c}{} \\
\hline
\end{tabular}

to a lesser extent, patients with lymph-node metastases may, in particular, benefit from blind treatment, as was shown in the study by Pacini et al. (10). This is in agreement with the opinion of some experts in the field, who have raised questions concerning the approach of blind treatment $(2,5,17)$. They argued that many of the blindly treated patients possibly have only very limited disease, which has little effect on their life expectancy. In such a case, the favourable outcome after blind treatment would be attributable to a very low tumor volume.

However, the results of our study supported the message of recent reports $(10,18,19)$ that the benefit of

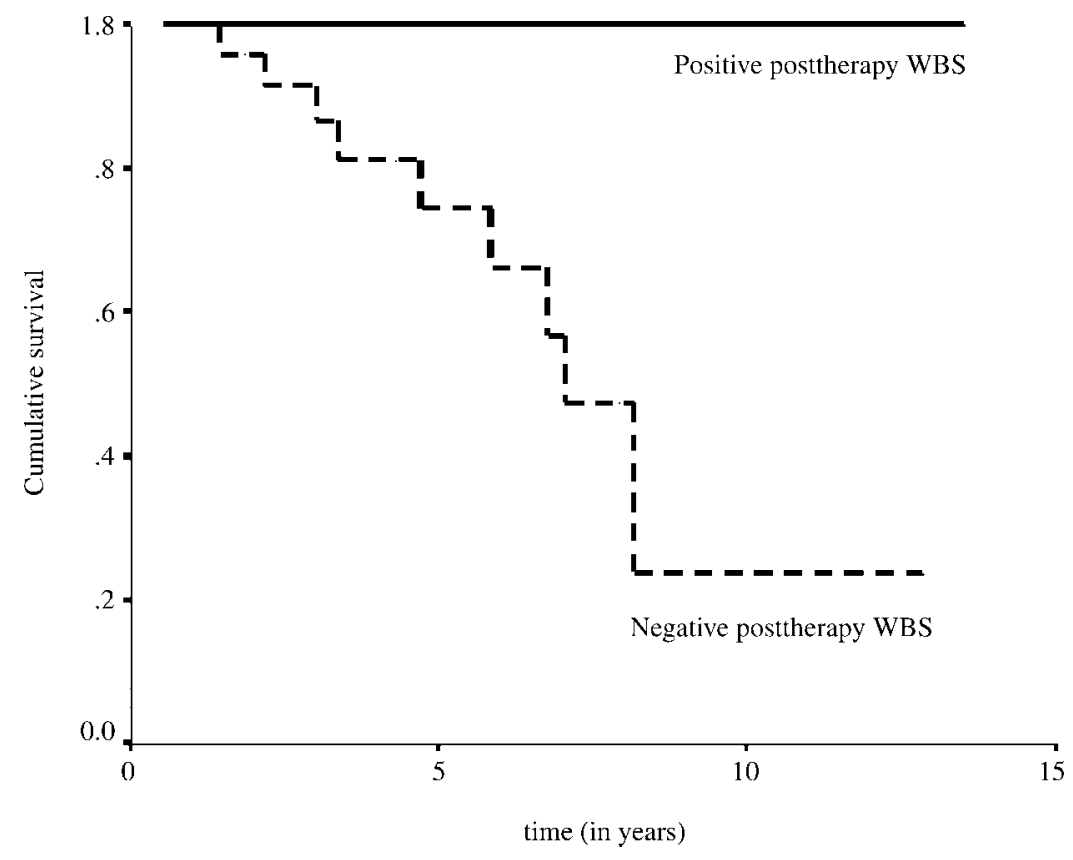

Figure 2 Overall survival of patients with positive and negative post-treatment WBS results. Five-year overall survival was $100 \%$ in the positive post-treatment group, compared with $76 \%$ in the negative post-treatment group $(P=0.001)$. 
Table 6 Summary of data from studies concerning blind treatment with high-dose ${ }^{131}$ I in patients with negative diagnostic ${ }^{131}$ I scanning.

\begin{tabular}{|c|c|c|c|c|c|}
\hline & $\begin{array}{l}\text { No. of patients } \\
\text { studied }\end{array}$ & $\begin{array}{l}\text { No. of patients with } \\
\text { negative DxWBS } \\
\text { and treated blindly }\end{array}$ & $\begin{array}{l}\text { No. of patients with } \\
\text { positive RxWBS } \\
\text { after blind treatment }\end{array}$ & $\begin{array}{l}\text { Duration of } \\
\text { follow-up }\end{array}$ & Results and outcome \\
\hline $\begin{array}{l}\text { Pachucki \& } \\
\text { Burmeister (24) }\end{array}$ & 21 & 7 & $4(57 \%)$ & $1.5-34$ months & No data \\
\hline $\begin{array}{l}\text { Mazzaferri \& } \\
\text { Kloos (16) }\end{array}$ & 10 & 10 & $8(80 \%)$ & $2-4$ years & $\begin{array}{l}3 \text { no uptake on post-therapy scan and Tg-off }<5 \mathrm{ng} / \mathrm{ml} \text {; } \\
\text { no further information }\end{array}$ \\
\hline Ronga et al. (23) & 61 & 11 & $8(73 \%)$ & Not given & $\begin{array}{l}\text { No follow-up data in positive RxWBS group. One of the } \\
3 \text { patients with negative RxWBS had progressive disease } \\
\text { within } 5 \text { months }\end{array}$ \\
\hline de Keizer et al. (15) & 22 & 16 & $11(69 \%)$ & 1 year & $\begin{array}{l}\text { Decrease in Tg-off in } 9 \text { patients with positive RxWBS and in } \\
3 \text { with negative RxWBS. Tg-off never became undetectable }\end{array}$ \\
\hline Pacini et al. (6) & 17 & 17 & $16(94 \%)$ & $\begin{array}{l}\text { In } 12 \text { patients; } \\
\text { up to } 2 \text { years }\end{array}$ & $\begin{array}{l}\text { At last follow-up, decrease in serum Tg (-off ?) in } 7 \text { and an } \\
\text { increase in } 1 \text { patient }\end{array}$ \\
\hline Pineda et al. (13) & 17 & 17 & $16(94 \%)$ & $\begin{array}{l}6 \text { months to } 5 \\
\text { years }\end{array}$ & $\begin{array}{l}\text { Decrease in Tg-off in } 13 / 16 \text { after the first blind treatment } \\
\text { and in } 5 \text { patients receiving a third blind dose. Tg-off } \\
\text { never became undetectable }\end{array}$ \\
\hline $\begin{array}{l}\text { Fatourechi et al. } \\
\text { (18) }\end{array}$ & 24 & 24 & $6(25 \%)$ & $6-33$ months & $\begin{array}{l}\text { Tg-on after measured in } 18 \text { patients increased. } 5 \text { patients died, } \\
4 \text { of them with negative RxWBS, } 1 \text { with partial negative } \\
\text { RxWBS (no uptake in bone metastases) }\end{array}$ \\
\hline Schaap et al. (19) & 39 & 39 & $22(60 \%)$ & Up to 15 months & $\begin{array}{l}\text { Tg-on atter in positive RxWBS group decreased }(P=0.035) \text { and } \\
\text { increased }(P=0.006) \text { in negative RxWBS group. } \\
\text { Follow-up by radiological response: better }(P=0.049) \text { in positive } \\
\text { RxWBS group. No data about clinical outcome }\end{array}$ \\
\hline Pacini et al. (10) & 70 & 42 & $30(71 \%)$ & $\begin{array}{l}\text { Mean } 6.7 \pm 3.8 \\
\text { years }\end{array}$ & $\begin{array}{l}\text { Decrease in Tg-off in } 19 \text { patients with positive RxWBS. CR in } \\
33 \% \text { of patients with positive RxWBS, in } 17 \% \text { with negative } \\
\text { RxWBS and in } 68 \% \text { of the untreated patients }\end{array}$ \\
\hline $\begin{array}{l}\text { van Tol et al., } \\
\text { present study }\end{array}$ & 56 & 56 & $28(50 \%)$ & $\begin{array}{l}\text { Mean } 4.5 \pm 2.9 \\
\text { years }\end{array}$ & $\begin{array}{l}\text { No change in Tg-on prior and Tg-on after in both groups. } \\
\text { CR in } 64 \% \text { of patients with positive RxWBS and in } 36 \% \\
\text { with negative RxWBS }\end{array}$ \\
\hline
\end{tabular}

DxWBS, diagnostic whole-body scan; RxWBS, post-treatment whole-body scan; Tg-on, Tg during thyroid hormone suppression therapy; Tg-off, Tg after thyroid hormone withdrawal; CR, complete remision. 
blind treatment for the clinical course in patients with negative post-treatment WBS is doubtful. Pacini et al. (10) had followed 12 patients with negative WBS after high-dose blind treatment during a period of 6 years. Eight of these 12 patients showed undetectable Tg-on after treatment, but 10 had clinical or biochemical (detectable Tg-on) evidence of disease and one patient had died as a consequence of the disease. Fatourechi et al. (18) showed an increase in Tg-on after blind treatment in 24 patients with differentiated carcinoma, 18 of them with a negative post-treatment scan. Five patients died in the follow-up period between 0.5 and 3 years. Schaap et al. (19) reported 39 patients with both follicular and papillary cancer, 17 of them with a negative post-treatment scan. Tg-on in these 17 patients showed an increase after high-dose ${ }^{131} \mathrm{I}$ therapy; 13 had progressive disease. Using non-linear regression of multiple Tg-off values, Schaap and colleagues showed no harmful effects of additional high-dose ${ }^{131}$ I treatment in the group with negative results post-treatment; however, there was limited follow-up after treatment. Table 6 shows the outcome of blind treatment in patients in other studies.

In our group of patients, the blind treatment did not lead to a significant change in serum concentrations of Tg-on in patients with either positive or negative posttreatment WBS. This can possibly be explained by the use of Tg-on concentrations before and after treatment with ${ }^{131}$ I. As has been shown above (Table 3), a considerable number of patients had an undetectable Tg-on before and after ${ }^{131}$ I treatment. Unfortunately, our treatment procedure did not allow us to use Tg-off concentrations after ${ }^{131} \mathrm{I}$ treatment. An additional explanation for the lack of effect on Tg-on concentrations may be the localization of ${ }^{131} \mathrm{I}$ uptake in our patient group. Iodine uptake was found mostly in the neck and mediastinum, whereas the therapeutic effect of the blind treatment, in the study by Pacini $e t$ al. (10) in particular, was found in the patients with lung metastases.

In our study, the difference in outcome after blind treatment between the patients with a positive and a negative post-treatment WBS is clear. The effects on outcome in the patients with positive post-treatment WBS results can be ascribed to the effects of iodine treatment, in agreement with others $(10,13,15)$. However, it can also be explained by tumor characteristics. The presence of radioiodine uptake after high-dose ${ }^{131} \mathrm{I}$ treatment reflects the selection of patients with a less aggressive tumor. Loss of differentiation of thyroid cancer cells is accompanied by the loss of thyroid-specific functions. The loss of iodine accumulation, caused by decreased expression of the $\mathrm{Na}^{+} / \mathrm{I}^{-}$symporter, is commonly regarded as one of the first steps in dedifferentiation (26). It is well known that differentiated thyroid cancer, which loses the ability to accumulate radioiodine, has a worse prognosis $(27,28)$. The ability to take up iodine reflects a well-differentiated grade of tumor cell, and may also contribute to the more favorable outcome in the group with positive WBS findings.

Our study thus confirms the use of high-dose ${ }^{131} \mathrm{I}$ treatment in patients with negative diagnostic ${ }^{131} \mathrm{I}$ WBS and detectable serum Tg-off as a diagnostic and prognostic tool. As proposed by Pacini et al. (10), the treatment with ${ }^{131}$ I should be based on the results of the first post-treatment scan and should, in particular, be adjusted in patients with lung metastases. Lymphnode metastases must be treated surgically if possible. No treatment should be used in those patients who demonstrate iodine uptake in the thyroid bed or in those without any uptake, because normalization of serum Tg-on and Tg-off values can occur, even in the absence of treatment $(10,25)$. The results of other diagnostic procedures such as neck ultrasonography, computed tomography scanning, magnetic resonance imaging or scans with non-specific isotopic tracers - including thallium-201, technetium-99mlabeled sestamibi or fluorine-18-labeled fluorodeoxyglucose positron emission tomography - must be taken into account when alternative forms of treatment are being chosen. In patients with a negative post-treatment scan the decision not to administer further treatment with high-dose iodine seems rational. In patients with a positive post-treatment WBS, the decision to give a further treatment with iodine depends on the location of the metastatic site and the possibility of other therapeutic options, such as surgery.

\section{Acknowledgements}

This study was supported by a grant from 'De Vereniging voor Academische Ziekenhuizen' and the University Hospital Groningen, The Netherlands.

\section{References}

1 Schlumberger MJ. Papillary and follicular thyroid carcinoma. New England Journal of Medicine 1998338 297-306.

2 Wartofsky L. An approach to the management of patients with scan negative, thyroglobulin positive, differentiated thyroid carcinoma. In Thyroid Cancer. A Comprehensive Guide to Clinical Management, pp 251-261. Ed. L Wartofsky. Totowa, New Jersey: Humana Press Inc., 2000.

3 Ozata M, Suzuki S, Miyamoto T, Liu RT, Fierro-Renoy F \& DeGroot LJ. Serum thyroglobulin in the follow-up of patients with treated differentiated thyroid cancer. Journal of Clinical Endocrinology and Metabolism 1994 79 98-105.

4 Schlumberger M \& Baudin E. Serum thyroglobulin determination in the follow-up of patients with differentiated thyroid cancer. European Journal of Endocrinology 1998138 249-252.

5 Mazzaferri EL. Treating high thyroglobulin with radioiodine: a magic bullet or a shot in the dark? Journal of Clinical Endocrinology and Metabolism $1995 \mathbf{8 0} 1485-1487$.

6 Pacini F, Lippi F, Formica N, Elisei R, Anelli S, Ceccarelli C et al. Therapeutic doses of iodine-131 reveal undiagnosed metastases in thyroid cancer patients with detectable serum thyroglobulin levels. Journal of Nuclear Medicine 198728 1888-1891. 
7 Schlumberger M, Mancusi F, Baudin E \& Pacini F. 131-I therapy for elevated thyroglobulin levels. Thyroid 19977 273-276.

8 Wartofsky L, Sherman SI, Gopal J, Schlumberger M \& Hay ID. Therapeutic controversy: the use of radioactive iodine in patients with papillary and follicular thyroid cancer. Journal of Clinical Endocrinology and Metabolism $1998 \mathbf{8 2} 4195-4203$.

9 Cailleux AF, Baudin E, Travagli JP, Ricard M \& Schlumberger M. Is diagnostic iodine-131 scanning useful after total thyroid ablation for differentiated thyroid cancer? Journal of Clinical Endocrinology and Metabolism $2000 \mathbf{8 5} 175-178$.

10 Pacini F, Agate L, Elisei R, Capezzone M, Ceccarelli C, Lippi F et al. Outcome of differentiated thyroid cancer with detectable serum $\mathrm{Tg}$ and negative diagnostic ${ }^{131} \mathrm{I}$ whole body scan: comparison of patients treated with high ${ }^{131} \mathrm{I}$ activities versus untreated patients. Journal of Clinical Endocrinology and Metabolism 2001 86 4092-4097.

11 Schlumberger M, Arcangioli O, Pierkaski JD, Tubiana M \& Parmentier C. Detection and treatment of lung metastases of differentiated thyroid carcinoma in patients with normal chest X-rays. Journal of Nuclear Medicine 198829 1790-1794.

12 Sherman SI, Tielens ET, Sostre S, Wharam MD \& Ladenson PW. Clinical utility of posttreatment radioiodine scans in the management of patients with thyroid carcinoma. Journal of Clinical Endocrinology and Metabolism 199478 629-634.

13 Pineda JD, Lee T, Ain K, Reynolds JC \& Robbins J. Iodine-131 therapy for thyroid cancer patients with elevated thyroglobulin and negative diagnostic scan. Journal of Clinical Endocrinology and Metabolism $1995 \mathbf{8 0} 1488-1492$.

14 Brendel AJ, Lambert B, Guyot M, Jeandot R, Dubourg H, Roger P et al. Low levels of serum thyroglobulin after withdrawal of thyroid suppression therapy in the follow-up of differentiated thyroid carcinoma. European Journal of Nuclear Medicine 1990 $1635-38$

15 de Keizer B, Koppeschaar HPF, Zelissen PMJ, Lips CJM, van Rijk RP, van Dijk A et al. Efficacy of high therapeutic doses of iodine-131 in patients with differentiated thyroid cancer and detectable serum thyroglobulin. European Journal of Nuclear Medicine 2001281 198-202.

16 Mazzaferri EL \& Kloos RT. Current approaches to primary therapy for papillary and follicular thyroid cancer. Journal of Clinical Endocrinology and Metabolism 200186 1447-1463.

17 McDougall IR. 131-I treatment of 131-I negative whole body scans, and positive thyroglobulin in differentiated thyroid carcinoma: what is being treated? Thyroid $19977669-672$.

18 Fatourechi V, Hay ID, Javedan H, Wiseman GA, Mullan B \& Gorman CA. Lack of impact of radioiodine therapy in Tg-positive, diagnostic whole-body scan-negative patients with follicular cell-derived thyroid cancer. Journal of Clinical Endocrinology and Metabolism 200287 1521-1526.
19 Schaap J, Eustatia-Rutten CFA, Stokkel M, Links TP, Diamant M, van der Velde E et al. Does radioiodine therapy have disadvantageous effects in non-radioiodine accumulating differentiated thyroid cancer? Clinical Endocrinology 200257 117-124.

20 Sera N, Ashizawa K, Ando T, Ide A, Abe Y, Usa T et al. Anaplastic changes associated with p53 gene mutation in differentiated thyroid carcinoma after insufficient radioactive iodine (131I) therapy. Thyroid $2000 \mathbf{1 0} 975-979$.

21 Cholewinski SP, Yoo KS, Klieger PS \& O'Mara RE. Absence of thyroid stunning after diagnostic whole body scanning with $185 \mathrm{MBq}$. Journal of Nuclear Medicine 200041 1198-1202.

22 van Tol KM, Hew JM, Jager PL, Vermey A, Dullaart RPF \& Links TP. Embolization in combination with radioiodine therapy for bone metastases of differentiated thyroid carcinoma. Clinical Endocrinology 200052 653-659.

23 Ronga G, Fiorentino A, Paserio E, Signore A, Todino V, Tummarello MA et al. Can iodine-131 whole-body scan be replaced by thyroglobulin measurements in the post-surgical follow-up of differentiated thyroid carcinoma? Journal of Nuclear Medicine 199031 1766-1771.

24 Pachucki J \& Burmeister LA. Evaluation and treatment of persistent thyroglobulinaemia in patients with well-differentiated thyroid cancer. European Journal of Endocrinology 1997137 254-261.

25 Baudin E, Do Cao C, Cailleux AF, Leboulleux S, Travagli JP \& Schlumberger M. Positive predicitive value of serum thyroglobulin levels, measured during the first year of follow-up after thyroid hormone withdrawal, in thyroid cancer patients. Journal of Clinical Endocrinology and Metabolism $2003 \mathbf{8 8} 1107-1111$.

26 Lazar V, Bidart JM, Caillou B, Mahe C, Lacroix L, Filetti S et al. Expression of the $\mathrm{Na}^{+} / \mathrm{I}^{-}$symporter gene human thyroid tumors: a comparison study with other thyroid-specific genes. Journal of Clinical Endocrinology and Metabolism $1999843228-3234$.

27 Maxon HR \& Smith HS. Radioiodine-131 in the diagnosis and treatment of metastatic well differentiated thyroid cancer. Endocrinology and Metabolism Clinics of North America 199019 $685-718$.

28 Lubin E, Mechlis-Frish S, Zatz S, Shimoni A, Segal K, Avraham A et al. Serum thyroglobulin and iodine-131 whole-body scan in the diagnosis and assessment of treatment for metastatic differentiated thyroid carcinoma. Journal of Nuclear Medicine 199435 $257-262$

Received 30 December 2002

Accepted 26 March 2003 